as predicted by the model. These results show how a simple cost-benefit theory can predict (as opposed to Durham's post hac explanation) the occurrence of territorial competition for food in honeycreepers, although the authors suggest that an important additional factor is that the territorial birds defend more food than they need in the short term, perhaps as an insurance against hard times.

\section{Man's impact on nature}

\author{
from Egon $T$. Degens
}

A Dahlem Conference on Global Chemical Cycles and their Alterations by Man was held in West Berlin on November 15-19, 1976. It was organised by Dr Silke Bernhard from whom further details may be obtained at Dahlem Konferenzen, D-1000 Berlin 33.

WHEN man started to cut forest, burn steppe and plough land, the balanced system of air, water, life and soil was gradually disturbed. Through this type of land management, soil erosion rates quadrupled over the past 2,000 years and were borne with all their side effects by the environment, almost unnoticed by man. Industrial revolution and a growing population accelerated man's insult to nature to a point that the potential dangers are now inescapably apparent. Concerned people throughout the world are asking the now familiar questions: what is the present state of the global environment, where are we heading if increase in gross national product has higher priority than conservation, and what immediate steps are to be taken to improve the quality of the environment? At the most recent of the Dahlem Konferenzen, social and natural scientists addressed themselves again to some of these questions, though it was interesting to note that no member of the third world countries attended.

Some fourteen background papers (most of which, in my opinion, were rather catholic, indicating that we cannot yet give precise answers to global enquiries) elicited hundreds of written comments and questions. It was frustrating that only a few could be picked up in the general discussion.

Four groups addressed themselves respectively to the topics of models, modulations, and controls; fossil fuel burning and its effect on the biosphere and on sedimentary cycles; source functions: combustion products of fossil fuels, radionuclides and heat; and the resilience of the environment and of human society to changes in energy use. But it turned out that there is no way to deal reasonably with such an involved bundle of items, at least not during a five day session. Each group independently selected a few critical areas for discussion and almost identical key issues came up in the four huddles--man's impact on the global carbon, nitrogen, oxygen, phosphorous and sulphur cycles, and the interaction of $\mathrm{C}-\mathrm{N}-\mathrm{O}-\mathrm{P}-\mathrm{S}$ compounds with nature through these cycles.

Questions of immense importance turned out to have tremendously large uncertainties. One example may be taken-the question of whether global biomass is increasing or decreasing? Geochemists say it must increase, because they have a hard time finding another potential sink for the 'missing $\mathrm{CO}_{2}{ }^{\prime}$ in the atmosphere. This is so because, of the $4.6 \times 10^{\circ}$ tons of combusted carbon emitted every year as $\mathrm{CO}_{2}$ into the air, only about $50 \%$ remains there; the rest apparently goes elsewhere, and it's not into the ocean. In contrast, biologists say the global biomass may remain steady or even decrease, partly as a result of excessive cutting of wood. They even believe that deforestation and the accompanying oxidation of wood and humus is a significant contributor of $\mathrm{CO}_{2}$ to the air, and values between $1 \times 10^{\circ}$ and $5 \times 10^{9}$ tons of $\mathrm{C}$ could be annually released to the air if one uses some of the published figures.

So it seems that the increase in atmospheric $\mathrm{CO}_{2}$ is not solely due to the burning of fossil fuel but that deforestation is also an important pollutant. How can we reverse this trend? Should we plant a trillion trees, as somebody suggested? But to be realistic, there is no way out than to cut $\mathrm{CO}_{2}$ emission to the atmophere over the next 20 years or man will be warm but very, very sorry. Although the climate curve shows a cooling trend at present, only a minority of one-and-ahalf was of the opinion that the impact of man-made $\mathrm{CO}_{2}$ on climate is beneficial. As well as producing $\mathrm{CO}_{2}$, fire and fossil fuel burning also release particles to the air. How do these affect global climate? Does stratospheric light-scattering by particles lower world temperatures or are the particles more efficient absorbers than scatterers and thus raise the global temperature? No opinion one way or the other was arrived at.

Equally uncertain were questions of the significance of man's perturbation of the ozone layer compared with natural perturbations. What are the quantitative effects of aerosols, $\mathrm{N}_{2} \mathrm{O}$, or $\mathrm{CO}$ ? It turned out that the data base for ozone is not good. There are not only chemical but meteorological changes and not all participants shared the view that man causes the altera- tions noticed in the ozone layer. Are we kidding ourselves, because we ask questions on these and related issues that we cannot answer? The whole reputation of science is at stake, because in the past so much has been made of spray cans, fuel combustion and other environmental hazards caused by man's activities. The scientist's role is to bring about a change in technological approaches, which may lighten the burden on nature and at the same time help to fulfill the social needs of all the people in the world, and not just those from the developed countries. To accomplish this the scientist needs to put forward an exceptionally credible case, because the biggest inhibition of public action is disagreement among scientists.

In conclusion one of the finest results of the Dahlem Konferenz was that all participants tried to agree on the range of uncertainties, rather than being disappointed at not coming to a scientific consensus. There is a long way to go before global models of chemical cycles are universally accepted. At present the question of man's impact on sources and sinks of the biogenic elements is still up in the air.

\section{Why marsupials can't win}

\section{from Barry Cox}

ONE of the most intriguing problems in vertebrate evolution is the reason for the superiority of eutherians ('placentals') when competing with marsupials. Because they are so alike in their levels of morphological adaptation, it has long seemed likely that the cause lay within the fundamentally different patterns of reproductive physiology of the two groups. In an extremely interesting paper, Lillegraven (Evolution, 29, 707; 1976) has recently examined this possibility.

Lillegraven commences by reviewing a number of papers by Müller, whose contributions have been largely ignored (unread?) by English-speaking workers. Marsupials are born nearly helpless, at a very early stage of development, since they have a very short period of gestation. Muller has shown that their pouch young show several features adapted to life in the pouch, such as seals to close the lips around the nipple, to protect the eyes and to plug the external auditory meatus. All these adaptations occur fleetingly in the development of eutherians, strongly suggesting that they, too, originally had a developmental history like that of living marsupials.

Although Muller herself regards the marsupials and eutherians as having 